\title{
Cooling and Annealing Effect on Indentation Response of Lead-Free Solder
}

\author{
Xu Long*, ${ }^{*}$, Yihui Feng ${ }^{\dagger}$ and Yao Yao* \\ ${ }^{*}$ School of Mechanics, Civil Engineering and Architecture \\ Northwestern Polytechnical University \\ $X i$ 'an 710072, P. R. China \\ ${ }^{\dagger}$ State Key Laboratory of Nonlinear Mechanics \\ Institute of Mechanics, Chinese Academy of Sciences \\ Beijing 100190, P. R. China \\ ${ }^{\ddagger} x u l o n g @ n w p u . e d u . c n$
}

Received 20 March 2017

Revised 9 May 2017

Accepted 9 May 2017

Published 9 June 2017

\begin{abstract}
With the development of lead-free solders in the electronic packing industry, $\mathrm{Sn}-\mathrm{Ag}-\mathrm{Cu}$ solders are one of the most promising lead-free alloys to be applied due to their outstanding mechanical property and wettability. By performing indentation experiments, the effect of cooling rate on the mechanical properties of $\mathrm{Sn}-3.0 \mathrm{Ag}-0.5 \mathrm{Cu}$ (SAC305) solder is investigated in typical cooling conditions (i.e., furnace cooled and water quenched) and compared with the as-machined samples of bulk solder bars from the industry. Based on continuous stiffness measurement technique, Young's modulus and hardness are reduced by $2.3-3.9 \mathrm{GPa}$ and $0.053-0.085 \mathrm{GPa}$, respectively, after annealing treatment for the indentation depth between $1000 \mathrm{~nm}$ and $1100 \mathrm{~nm}$ in samples after cooling, however, the value of hardness is independent of cooling condition. By defining the contact stiffness to represent residual stress in solder samples after cooling and annealing process, an exponential-based Oliver-Pharr model is employed to fit the unloading responses of indentation. It is found that the smaller cooling rate induces less contact stiffness and thus less residual stress. Despite different cooling conditions, the contact stiffness of unannealed and annealed solder samples are $711.8-842.5 \mu \mathrm{N} / \mathrm{nm}$ and $655.2-$ $673.4 \mu \mathrm{N} / \mathrm{nm}$, respectively. Thus, annealing treatment of $210^{\circ} \mathrm{C}$ for $6 \mathrm{~h}$ can effectively alleviate residual stress to a similar level for SAC305 solder samples with different cooling conditions. This conclusion is supported by the alleviation of pile-up deformation in the residual indentation after annealing treatment.
\end{abstract}

Keywords: Lead-free solder; cooling condition; annealing; mechanical property; residual stress.

\section{Introduction}

Lead-free solders are replacing conventional lead-rich solder alloys as legislated by RoHS European Union, 2003 due to the concerns to environment and human health. Because of the outstanding mechanical property and wetting behavior, $\mathrm{Sn}-\mathrm{Ag}-\mathrm{Cu}$ solders are the most potential alternatives, attracting wide attention 
for reliability investigations. Compared with other solders with higher Ag content especially when low cooling rates are applied, $\mathrm{Sn}-3.0 \mathrm{Ag}-0.5 \mathrm{Cu}(\mathrm{SAC} 305)$ solder is a good choice to ensure structural integrity without forming large brittle intermetallic compound $\mathrm{Ag}_{3} \mathrm{Sn}$, which is likely to crack and degrade the ductility of solder Kim et al., 2002].

As one of the most important process variables Yang et al., 1995, cooling condition significantly affects the mechanical property and microstructure of SAC solders. It was experimentally observed by Kim et al. 2002] that the saturated tensile stress increased by $28.4-71.7 \%$ for the tensile strain rate ranging from $10^{-4} / \mathrm{s}$ to $10^{-2} / \mathrm{s}$ when a rapid cooling rate was applied to $\mathrm{Sn}-3.5 \mathrm{Ag}-0.7 \mathrm{Cu}$ solder. Despite the presence of $\mathrm{Cu}_{6} \mathrm{Sn}_{5}$ particle reinforcement, higher shear strength was achieved for a thicker eutectic $\mathrm{Sn}-\mathrm{Ag}$ solder joint when the cooling rate of $5.5^{\circ} \mathrm{C} / \mathrm{s}$ was applied; meanwhile, this relationship between shear strength and joint dimension was not significant for a slower cooling rate of $2.3^{\circ} \mathrm{C} / \mathrm{s}$ [Sigelko et al., 1999]. Ochoa et al. 2003 experimentally studied the influence of cooling rate between $0.08^{\circ} \mathrm{C} / \mathrm{s}$ and $24^{\circ} \mathrm{C} / \mathrm{s}$ on $\mathrm{Sn}-3.5 \mathrm{Ag}$ solder. Their work correlated the mechanical property such as yield and ultimate tensile strengths, Young's modulus and fracture strain with microstructures to elucidate the underlying damage mechanism associated with Snmatrix microstructure and $\mathrm{Ag}_{3} \mathrm{Sn}$ morphology. The observed effect of cooling rate on microstructures is similar to the recent findings for the cooling rates between $1.2^{\circ} \mathrm{C} / \mathrm{s}$ and $6.6^{\circ} \mathrm{C} / \mathrm{s}$ by Hurtony et al. [2016]. In addition, Ochoa et al. [2004] evaluated the effect of cooling rate on the dominant mechanisms of creep behavior at the temperatures ranging from $25^{\circ} \mathrm{C}$ to $120^{\circ} \mathrm{C}$ based on stress exponent and activation energy. By comparing the effects of cooling rate and $\mathrm{Ag}$ content on $\mathrm{Sn}-1.0 \mathrm{Ag}-0.7 \mathrm{Cu}$ and $\mathrm{Sn}-2.0 \mathrm{Ag}-0.7 \mathrm{Cu}$ solders, Pereira et al. 2013. identified the secondary dendrite arm spacing to be closely related with micro-hardness, yield and ultimate tensile strength, as well as elongation to fracture based on the classical Hall-Petch relations.

As reviewed above, the effects of cooling rate on mechanical property and microstructure of lead-free solder alloys have been studied by different researchers; however, the residual stress in solder material obtained under different cooling conditions is not well known. Usually, annealing process is performed to stabilize the microstructure and alleviate residual stress, but the annealing effect on the mechanical property of SAC305 solder remains to be elucidated. In the current study, furnace cooled and water quenched conditions are considered to obtain candidate samples from molten solder. The machined samples from bulk solder bars are adopted for control test with the presence of both working stress from machining process and residual stress from cooling condition. A half of the prepared samples obtained by furnace cooled, water quenched and as-machined conditions are annealed at $210^{\circ} \mathrm{C}$ for $6 \mathrm{~h}$ to investigate the effect of annealing treatment on residual stress. In order to measure the mechanical property of annealed and unannealed solder samples solidified under different cooling conditions, the load-displacement responses from instrumented indentation experiments Jiang et al., 2012; Li et al., 2012; Liu et al., 2012] are interpreted. Particularly, an exponential-based Oliver-Pharr model is 
employed to fit the unloading stage of indentation response and calculate the corresponding contact stiffness to quantify the magnitude of residual stress.

\section{Specimen Preparation and Experimental Program}

The $96.5 \mathrm{Sn}-3.0 \mathrm{Ag}-0.5 \mathrm{Cu}$ (in wt.\%) alloy ingot was manufactured by Alpha Assembly Solutions to be free of cast in impurities or included oxides. The solder ingot was re-melted in an electrically heated furnace with Ti-gathered high purity atmosphere to avoid oxidation. Alloy plates with a thickness of $2 \mathrm{~mm}$ were made by casting into a copper mold surrounded by circulating water at a constant temperature of $20^{\circ} \mathrm{C}$. The molten alloy left in the furnace was cooled down naturally to room temperature. For the control test, as-machined solder samples of approximately $10.0 \mathrm{~mm} \times 10.0 \mathrm{~mm} \times 2.0 \mathrm{~mm}$ dimensions were obtained by machining solder ingots. The obtained water quenched plates and furnace cooled ingots were cut into the same dimension with as-machined solder samples.

The prepared samples from different cooling conditions were divided into two groups; the only difference is to undergo the annealing treatment at the temperature of $210^{\circ} \mathrm{C}$ for $6 \mathrm{~h}$ in an air heating furnace. All samples were mounted in PVC tubes by dental base acrylic resin powder which could gradually solidify at room temperature and did not release much heat to solder samples. In addition, solidified acrylic resin owned a satisfactory hardness to provide a matrix for solder samples during indentation tests. All the mounted samples were mechanically ground by $\mathrm{SiC}$ abrasive paper, polished with metal diamond suspension of $1.5 \mu \mathrm{m}$ to achieve a mirror-like surface, and eventually ultrasonically cleaned in ethanol. After being air dried, the obtained samples were stored at room temperature for more than 10 days to achieve a stable microstructure before indentation tests.

Based on a continuous stiffness measurement technique [Hay et al., 2010], a triangular pyramid Berkovich diamond indenter was employed in the Nano Indenter

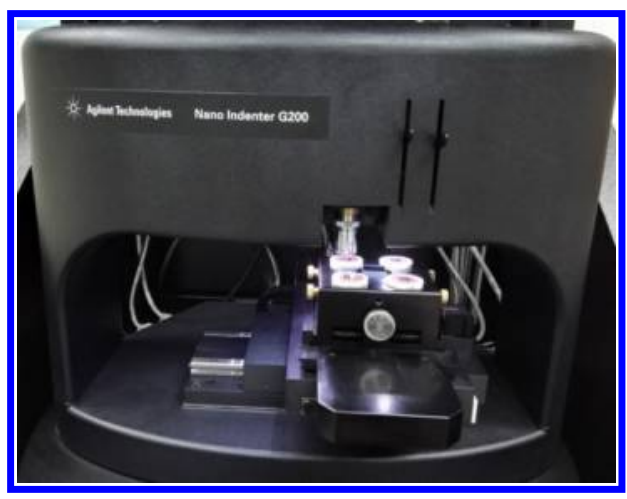

(a)

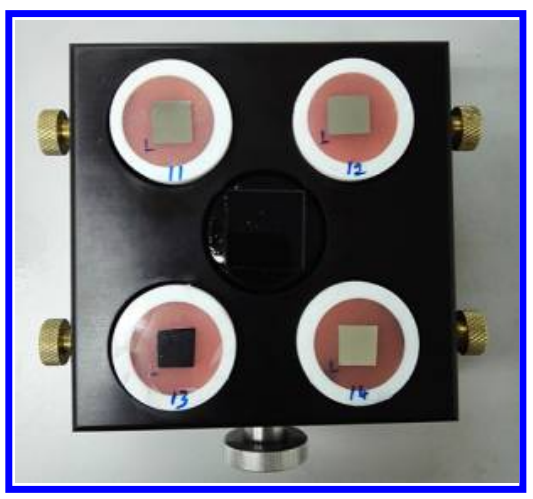

(b)

Fig. 1. Experimental instrument and samples for SAC305 solder. (a) Nano Indenter and (b) Solder samples to be tested. 


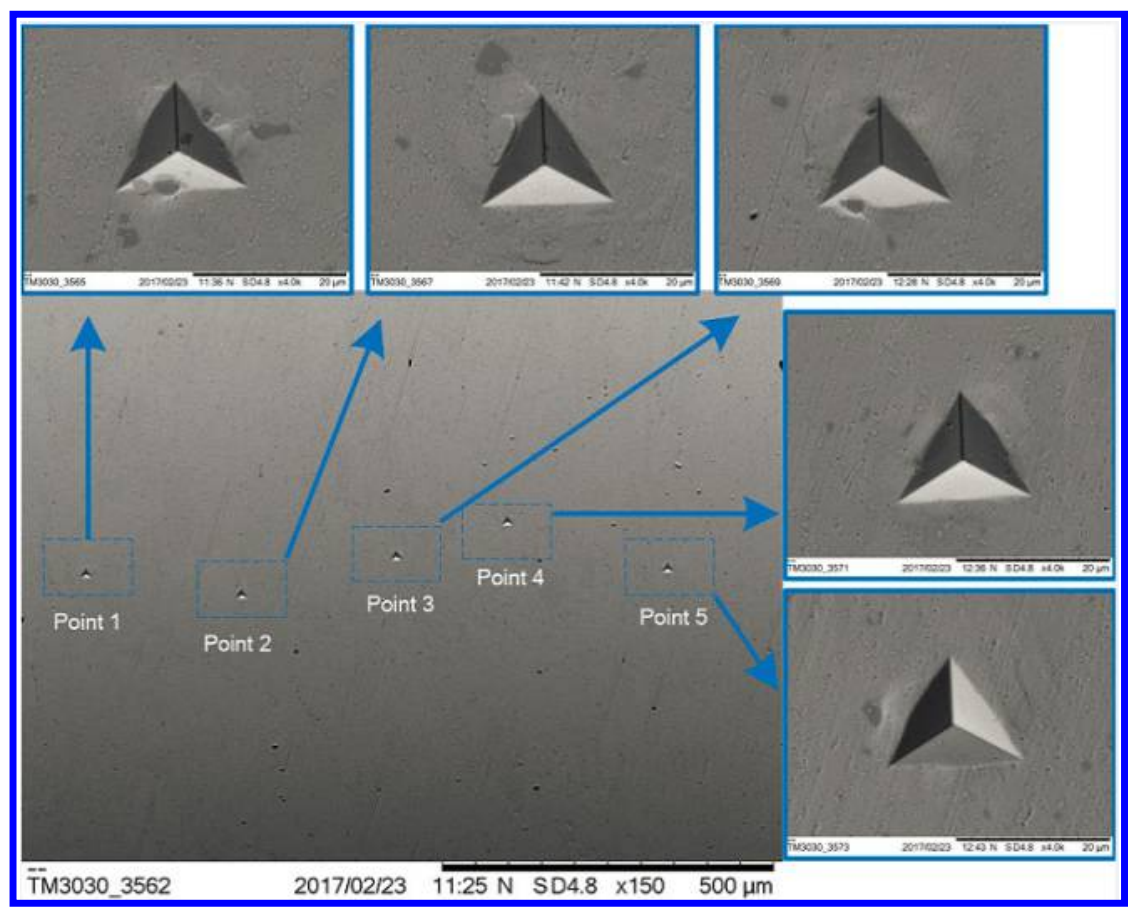

Fig. 2. Five indentations on each sample with a Berkovich diamond pyramid indenter.

G200 produced by Agilent Technologies, as shown in Fig. 1]. On each sample, five points are indented in an identical pattern as shown in Fig. 2. The indented points are sufficiently spaced to avoid the interaction of deformation. The maximum indentation depth was set to $2000 \mathrm{~nm}$ with a constant strain rate of $0.05 / \mathrm{s}$ at room temperature. Upon the maximum depth, the indenter was held for $10 \mathrm{~s}$ to alleviate the creep effect prior to the unloading stage.

\section{Experimental Results and Discussions}

\subsection{Load-penetration depth response}

Based on the measured load-depth curves at five sufficiently spaced positions, an averaged load-depth response to represent the mechanical property of SAC305 material can be obtained. For instance, the load-penetration depth responses measured for the water quenched solder sample are averaged as shown in Fig. 3(a). At the end of holding stage, the applied load on the indenter is unloaded by $90 \%$ firstly for thermal drift correction and then completely unloaded. So the unloading stage is discontinuous, as shown in Fig. 3.(b), and numerical regressions are only conducted for the upper $90 \%$ portion. It should be noted that the individual unloading response for each indentation is fitted as explained later to measure the residual stress. 


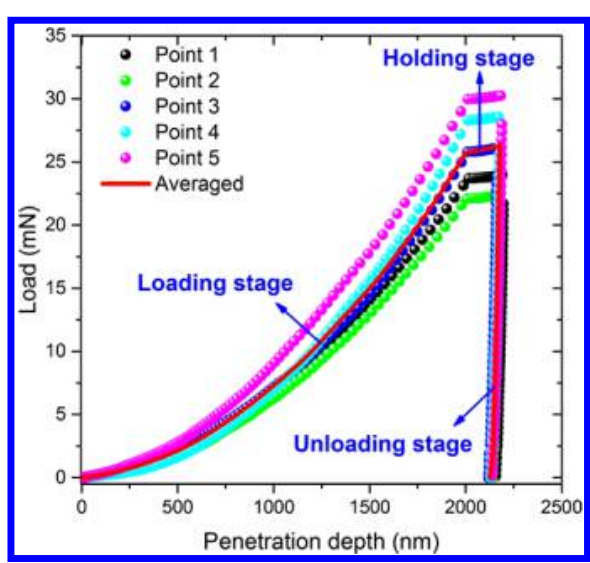

(a)

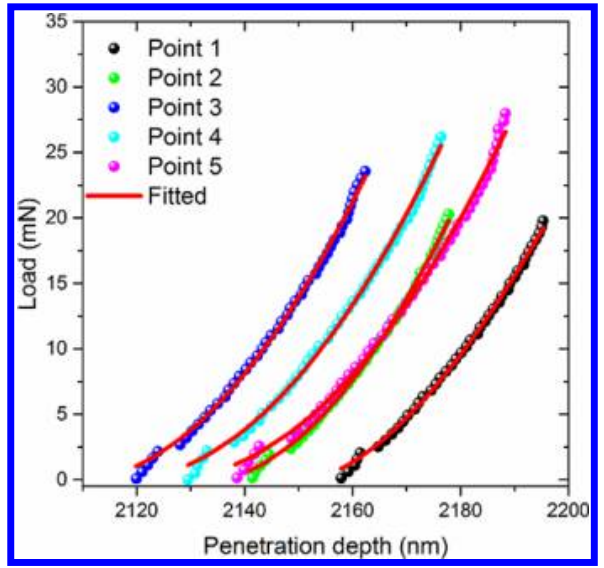

(b)

Fig. 3. Load-penetration depth responses measured by indentation for the water quenched sample without annealing treatment. (a) Load-penetration depth curves and (b) magnification of unloading stage of the curves in (a).

Another point has to be emphasized is the uniqueness of relationship between the load-penetration depth curve and the material properties of SAC305 solder material. Tho et al. 2005] performed extensively large deformation finite element analysis to study the response of elasto-plastic materials obeying power law strainhardening. It was found that the relationship between the load-penetration depth curve and the material properties of elasto-plastic materials is not one-to-one. Unique solution of elasto-plastic material properties can be determined from the load-penetration depth curves of two conical indenters with different apex angles as proposed by Swaddiwudhipong et al. 2005. Nevertheless, a specific set of material properties can lead to a unique load-penetration depth curve. Therefore, based on a certain state of material property in SAC305 solder, it is reasonable in the present study to interpret the effect of cooling and annealing effect on the load-penetration depth curve.

\subsection{Young's modulus and hardness}

In this study, a superior continuous stiffness measurement Hay et al., 2010 technique is utilized to measure the mechanical properties (i.e., Young's modulus and hardness) of SAC305 solder material continuously as functions of indentation depth. Essentially, a small force oscillation is superimposed on the semi-static pressing force on the indenter, the amplitude of force oscillation is carefully controlled to maintain the constant amplitude of $2 \mathrm{~nm}$ with a frequency of $45 \mathrm{~Hz}$ in the displacement oscillation. Meanwhile, the response of indenter is recorded by a frequency-specific amplifier.

The Young's modulus and hardness are measured for each indentation and the obtained values from repeated indentations for the same cooling and annealing 


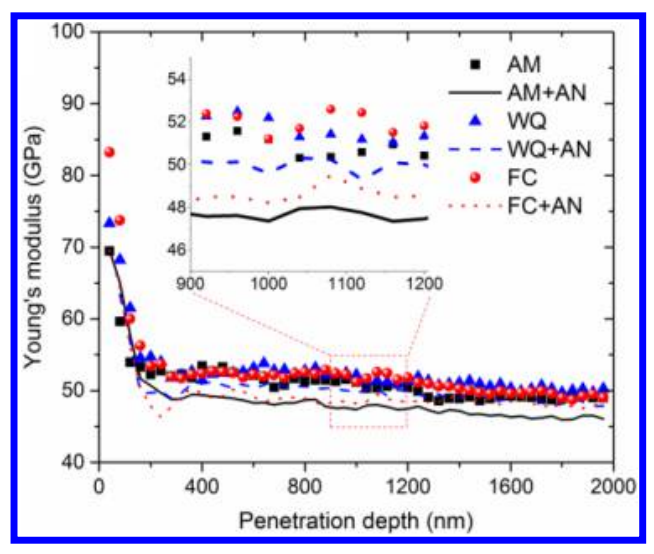

(a)

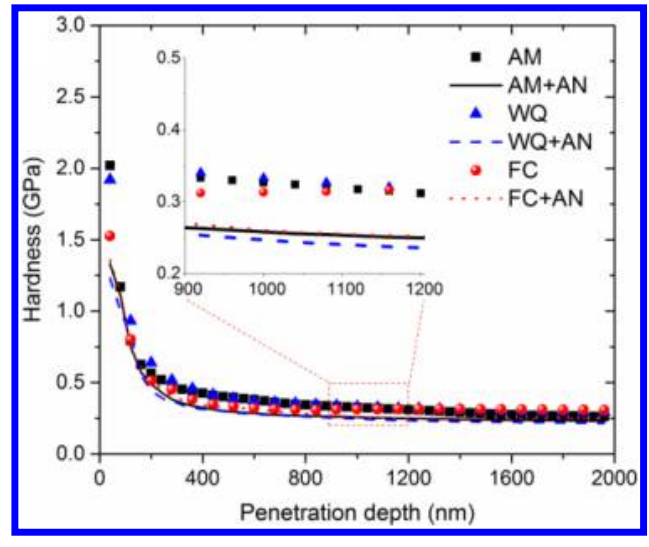

(b)

Fig. 4. Mechanical properties measured during indentation with inserts for penetration depth between $900 \mathrm{~nm}$ and $1200 \mathrm{~nm}$. (a) Young's modulus and (b) hardness.

condition are averaged in Fig. 4 As displayed in Fig. 4(a), the Young's modulus of SAC305 solder sample solidified in different cooling conditions after the annealing treatment is reduced by $2.3-3.9 \mathrm{GPa}$. To facilitate the legends of the figures, the as-machined condition, water quenched, furnace cooled conditions and annealing treatment are abbreviated as AM, WQ, FC and AN, respectively. As proposed by Ramakrishnan and Arunachalam 1993], Young's modulus $E$ is related to the porosity $\theta$ in the form of Eq. (11).

$$
E / E_{0}=(1-\theta)^{2} /\left(1+\kappa_{E} \theta\right),
$$

where $\kappa_{E}=2-3 v_{0}, v_{0}$ and $E_{0}$ is Poisson ratio and Young's modulus for the zeroporosity state. This relationship was validated against experimental data based on tensile tests and resonant ultrasound spectroscopy for $\mathrm{Sn}-3.5 \mathrm{Ag}$ solder Ochoa et al., 2003 . Therefore, it can be inferred that the annealing treatment is capable of healing microdefects formed during cooling to a certain extent.

Figure 4 (b) displays that the values of hardness under different cooling conditions are close for samples with and without annealing treatment, especially for the penetration depth range between $1000 \mathrm{~nm}$ and $1100 \mathrm{~nm}$. Moreover, annealing process effectively decreases solder hardness by $0.053-0.085 \mathrm{GPa}$ which is corresponding to the reduction of $17-26 \%$. In light of the positive linear relationship between hardness and yield strength for SAC305 solder [Xiao et al., 2014], it can be presumed that the yield strength of unannealed solder will be greater than that of annealed solder due to the higher hardness of unannealed solder samples.

\subsection{Creep behavior during the holding stage}

As illustrated in Fig. 3 a $10 \mathrm{~s}$ holding stage is experienced prior to the unloading stage. As the applied load on indenter is kept the same, creep deformation occurs 


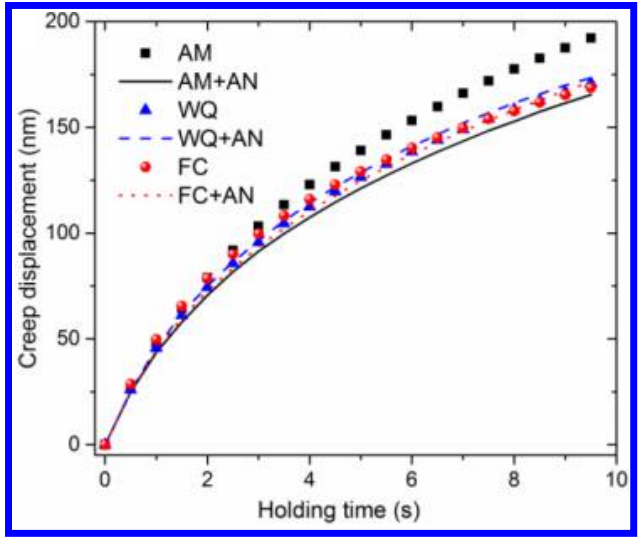

(a)

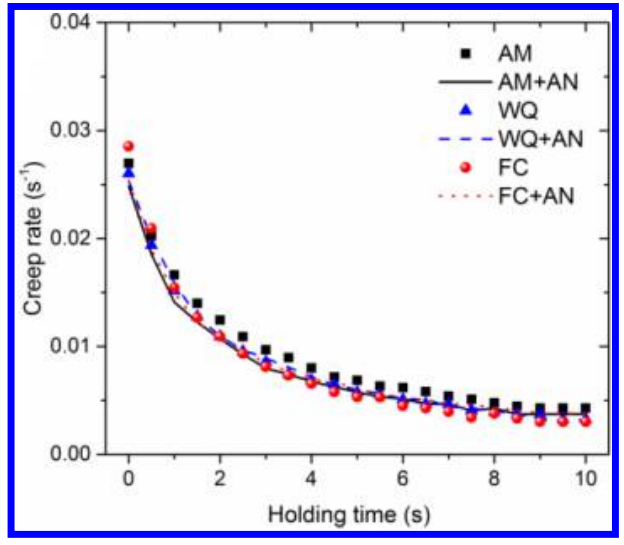

(b)

Fig. 5. Creep behavior during holding stage to release the creep deformation before unloading. (a) Creep displacement and (b) creep rate.

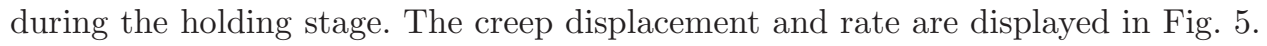
Apparently in Fig. 罒(a), the creep displacement of as-machined samples is greater compared with others from furnace cooled and water quenched conditions. This odd phenomenon does not result from cooling rate and is attributed to the work stress resulted from the machining process. It should be noted that after annealing treatment, the creep resistance of all solder samples are restored to the same level. Thus, annealing temperature of $210^{\circ} \mathrm{C}$ lasting for $6 \mathrm{~h}$ can effectively alleviate the work stress in SAC305 solder samples due to a machining process.

On the other hand, despite the slight scatter in creep displacement of unannealed samples solidifying at different cooling rates, the creep rate of annealed samples in Fig. [5 (b) is relatively stabilized. The creep rate is defined by Mayo and Nix [1988] as

$$
\dot{\varepsilon}_{c}=(d h / d t) / h,
$$

where $h$ represents the penetration depth and $t$ is the holding time. More importantly, the creep rate decays exponentially with the increase of holding time as shown in Fig. 5 (b). This means in addition to plastic deformation during the subsequent unloading stage, the holding stage of 10 s effectively removes creep deformation and leads to elastic recovery of indentation.

\subsection{Contact stiffness}

According to the Oliver-Pharr model Oliver and Pharr, 1992] as given in Eq. (2), the Belehradek model in OriginPro9.0 is adopted to perform numerical regressions of the unloading curves.

$$
P=A\left(h-h_{f}\right)^{m},
$$

where $h$ and $h_{f}$ represent the total and residual penetration depths of the indenter, respectively. For each load-penetration depth curve, the constant values of $A, h_{f}$ and 
Table 1. Parameters of curve fitting for unloading stage of indentation.

\begin{tabular}{lccc}
\hline Preparation condition & \multicolumn{3}{c}{ Parameters } \\
\cline { 2 - 4 } & $A$ & $h_{f}$ & $m$ \\
\hline As machined (AM) & 0.0110 & 2157.3 & 1.99 \\
As machined + annealed (AM + AN) & 0.0553 & 2130.8 & 1.72 \\
Water quenched (WQ) & 0.0161 & 2127.1 & 1.89 \\
Water quenched + annealing (WQ + AN) & 0.1117 & 2147.6 & 1.45 \\
Furnace cooled (FC) & 0.0560 & 2112.7 & 1.56 \\
Furnace cooled + annealing (FC + AN) & 0.0920 & 2139.3 & 1.50 \\
\hline
\end{tabular}

$m$ are best-fitted based on regression and listed in Table 1 with the abbreviations for different preparation conditions.

By differentiating the load with respect to the indentation depth $h$, the contact stiffness $S$ to describe the slope of the unloading path can be derived, and the maximum contact stiffness with the value of $h_{\max }$ is defined as

$$
S=\left.\frac{d P}{d h}\right|_{h=h_{\max }}=\alpha \cdot m\left(h_{\max }-h_{f}\right)^{m-1} .
$$

Regarding the scatter of curve-fitting parameters, the coefficients of variation are calculated as $0.702,0.0074$ and 0.130 , respectively. Therefore, the variation of parameter $h_{f}$ is negligible and can be approximated as a constant value. The changing trends of parameters $A$ and $m$ due to cooling and annealing effects are shown in Fig. [6 As indicated by the arrows, the annealing treatment consistently leads to the increase of parameter $A$ and the decrease of parameter $m$. Comparing the annealed and unannealed samples, the blue solid and dashed lines converge with the decrease of cooling rate, so the parameters $A$ and $m$ are closer and the influence

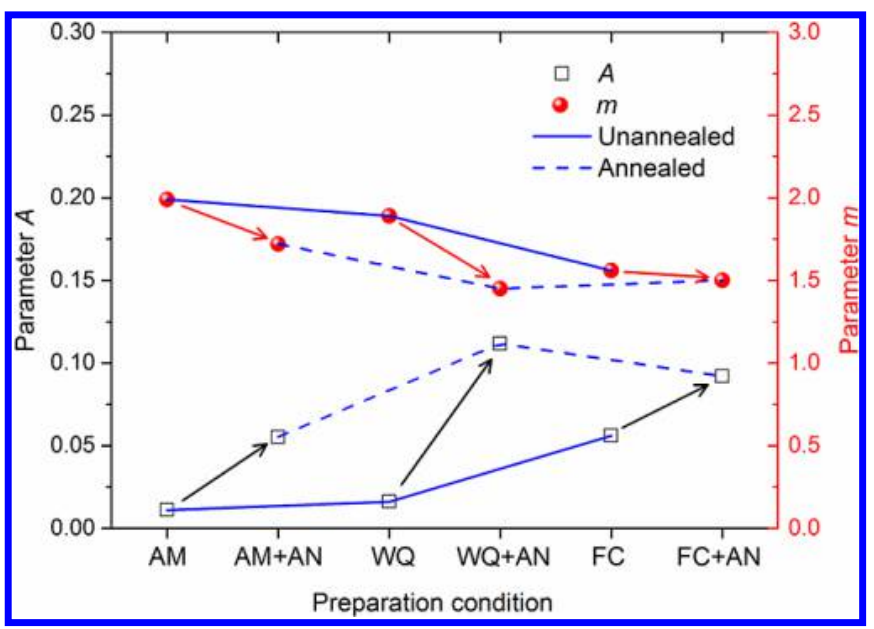

Fig. 6. Cooling and annealing effect on unloading response during indentation. 
of annealing process becomes limited for the furnace cooled condition. This means the mechanical property and microstructure in solder samples are more stabilized during a slower cooling condition.

The as-machined samples were obtained by machining the raw solder alloy ingots, which are formed by pouring molten solder at sufficiently high temperature into molds at room temperature. A similar approach of imposing cooling condition on molten solder by steel blocks was used by Sigelko et al. 1999. Their recorded cooling rate was $5.5^{\circ} \mathrm{C} / \mathrm{s}$ in the first $20 \mathrm{~s}$ and much greater in the very beginning of solidification. So, the cooling rate of manufacturing solder ingots in industry should be much faster than the cooling rate of $0.5-1.2^{\circ} \mathrm{C} / \mathrm{s}$ in air cooled conditions, and even greater than the rate of $24-25^{\circ} \mathrm{C} / \mathrm{s}$ in well-controlled water quenched conditions as reported by Ochoa et al. [2003] and Yang et al. [2015]. This explains why the curve fitted parameters of as-machined samples are similar to those of water quenched samples in Fig. 6]

The effect on the unloading stage has been investigated experimentally for alloys with different crystal structures such as copper $(\mathrm{Cu})$, ruthenium $(\mathrm{Ru})$, aluminum (Al), titanium (Ti) and steel Groth and Mann, 2012; Zhu et al., 2012], as shown in Fig. Z(a). It is noted that the steeper unloading slope (i.e., greater value of contact stiffness $S$ ) indicates greater magnitude of compressive residue stress. Contact stiffness according to the unloading responses is strongly related to the residual stress. By correlating the elastic recovery of indentation and residual stress for SAC305 material after different annealing treatments, Long et al. 2017] found that the residual stress has a positive linear relationship with contact stiffness. The maximum contact stiffness can be attained at the greatest penetration depths, which is displayed in Fig. 7(b) for both annealed and unannealed solder samples under

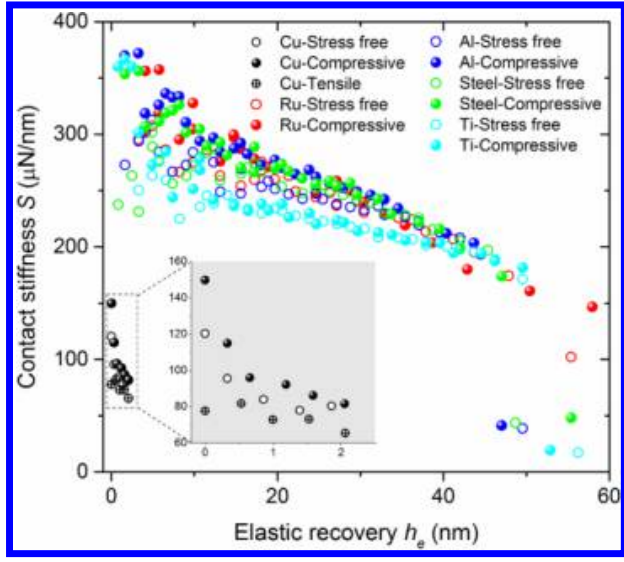

(a)

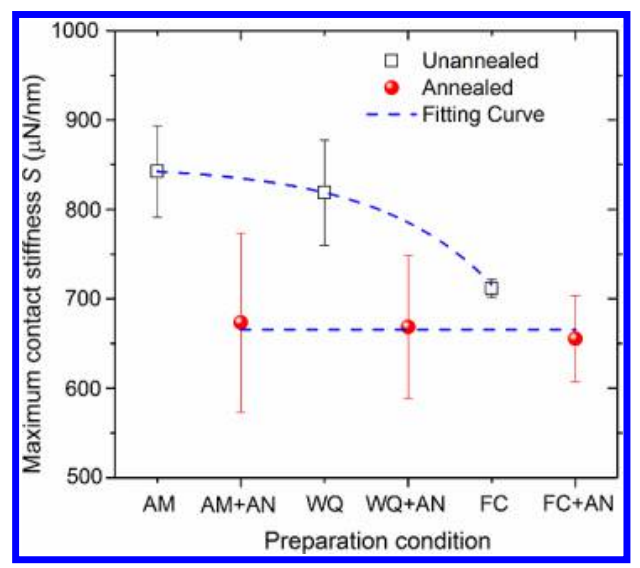

(b)

Fig. 7. Contact stiffness during unloading of indented samples. (a) Crystal structures as reported in the literature [Groth and Mann, 2012; Zhu et al., 2012] and (b) SAC305 under different preparation conditions. 
different cooling conditions. With the similar cooling rates, the contact stiffness for as-machined and water quenched samples are close to each other. As shown in Fig. [7(b), the contact stiffness of unannealed samples is between $711.8 \mu \mathrm{N} / \mathrm{nm}$ and $842.5 \mu \mathrm{N} / \mathrm{nm}$ and lower cooling rate in furnace cooled samples leads to smaller value of contact stiffness and standard derivation. However, the annealing treatment is capable of further decreasing the contact stiffness. The contact stiffness of annealed solder samples is between $655.2 \mu \mathrm{N} / \mathrm{nm}$ and $673.4 \mu \mathrm{N} / \mathrm{nm}$ and the average value is around $665.7 \mu \mathrm{N} / \mathrm{nm}$.

\subsection{Deformation of residual indentation}

The sides of residual indentation will bow out for soft material without further hardening capacity [Hay, 2009], which is called as pile-up deformation. As illustrated in Fig. 8, the pile-up deformation of unannealed solders is more remarkable compared with annealed solders, so it can be inferred that the hardening effect is removed by annealing treatment. This alleviation of pile-up deformation is more significant for the residual indentation of as-machined samples, which were obtained in an air cooled condition with a more rapid cooling rate. Therefore, the observed residual deformation of indentation from different preparation conditions supports the conclusions on the effect of cooling rate and annealing treatment.

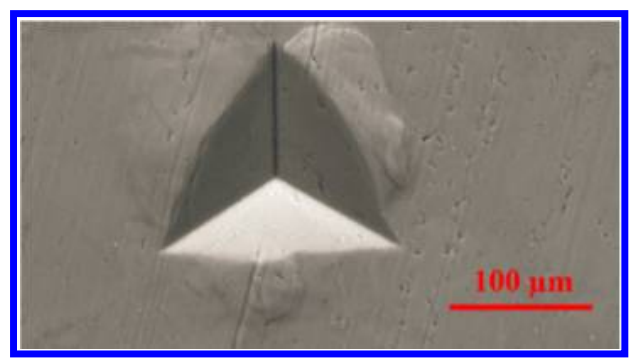

(a)

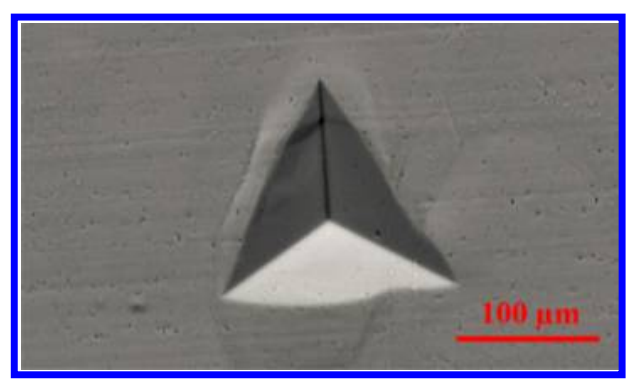

(c)

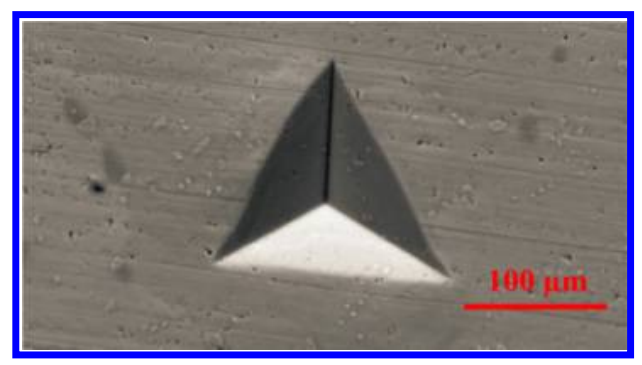

(b)

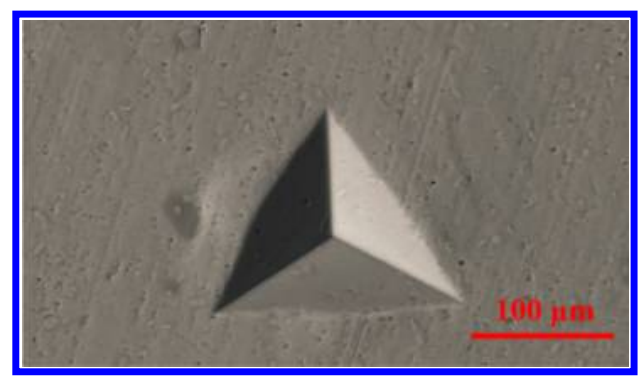

(d)

Fig. 8. Annealing effect on the pile-up deformation after indentation in samples under different preparation conditions. (a) $\mathrm{AM}$, (b) $\mathrm{AM}+\mathrm{AN}$, (c) FC and (d) FC+ AN. 


\section{Conclusions and Discussions}

Based on the experimental analysis, it is found that the mechanical property of SAC305 solder is significantly affected by the cooling rate. Thus, it is possible to achieve a desirable mechanical property by controlling the cooling rate when processing SAC305 bulk solder. Because a slower cooling rate can approach equilibrium cooling, the mechanical property in solder samples obtained in the furnace cool condition is more stabilized in terms of the reduction of Young's modulus and hardness. According to the Oliver-Pharr model, the fitted parameters $A$ and $m$ become closer, and the contact stiffness $S$ to represent residual stress is reduced with decreasing of the cooling rate. On the other hand, by applied annealing treatment to solder samples under different cooling conditions, the fitted parameters $A$ and $m$ converge to stable values at the furnace cooled condition, and the contact stiffness $S$ maintains the same magnitude of $665.7 \mu \mathrm{N} / \mathrm{nm}$. Therefore, the annealing treatment of $210^{\circ} \mathrm{C}$ for $6 \mathrm{~h}$ removes the effect of cooling condition on micromechanical property of SAC305 solder alloy.

It is well accepted that the microstructure of lead-free solder from a slower cooling condition is coarser and results in a lower resistance to dislocation motion. Based on the current study, it is reasonable to speculate that for solder obtained from a rapid cooling rate, the annealing treatment can provide more time to diffuse and achieve a microstructural state similar to that from an equilibrium cooling. However, this hypothesis requires further experimental investigation considering morphology evolution of tin-rich dendrite and distributed intermetallic compound particles.

\section{Acknowledgments}

This work was supported by National Natural Science Foundation of China (Grant Numbers 51508464 and 11572249), and the Fundamental Research Funds for the Central Universities (Grant Number 3102016ZY017).

\section{References}

European Union [2003] "95/EC of the European Parliament and of the Council of 27 January 2003 on the restriction of the use of certain hazardous substances in electrical and electronic equipment," Official Journal of the European Union L37, 19-23.

-Groth, B. P. and Mann, A. B. [2012] "Identifying changes in residual stress using indentation on machined metallic surfaces," Materials Letters 89, 287-290.

- Hay, J. [2009] "Introduction to instrumented indentation testing," Experimental Techniques 33(6), 66-72.

-Hay, J., Agee, P. and Herbert, E. [2010] "Continuous stiffness measurement during instrumented indentation testing," Experimental Techniques 34(3), 86-94.

-Hurtony, T., Szakál, A., Almásy, L., Len, A., Kugler, S., Bonyár, A. and Gordon, P. [2016] "Characterization of the microstructure of tin-silver lead free solder," Journal of Alloys $\&$ Compounds 672, 13-19. 
\Jiang, Z., Zhou, X., Zhu, Q., Zhao, Z., Wang, H., Prewett, P. D. and Jiang, K. [2012] "Recent study on the related problems in evaluation of mechanical properties for mems materials," International Journal of Applied Mechanics 1(04), $765-779$.

-Kim, K. S., Huh, S. H. and Suganuma, K. [2002] "Effects of cooling speed on microstructure and tensile properties of $\mathrm{Sn}-\mathrm{Ag}-\mathrm{Cu}$ alloys," Materials Science and Engineering: A 333(1-2), 106-114.

Li, T. L., Lee, J. H. and Gao, Y. F. [2012] "An approximate formulation of the effective indentation modulus of elastically anisotropic film-on-substrate systems," International Journal of Applied Mechanics 1(03), 515-525.

Liu, Z., Harsono, E. and Swaddiwudhipong, S. [2012] "Material characterization based on instrumented and simulated indentation tests," International Journal of Applied Mechanics 1(01), 61-84.

Long, X., Wang, S., Feng, Y., Yao, Y. and Keer, L. M. [2017] "Annealing effect on residual stress of $\mathrm{Sn}-3.0 \mathrm{Ag}-0.5 \mathrm{Cu}$ solder measured by nanoindentation and constitutive experiments," Materials Science and Engineering: A 696, 90-95.

Mayo, M. J. and Nix, W. D. [1988] "A micro-indentation study of superplasticity in Pb, Sn, and Sn-38 wt\% Pb," Acta Metallurgica 36(8), 2183-2192.

Ochoa, F., Deng, X. and Chawla, N. [2004] "Effects of cooling rate on creep behavior of a Sn-3.5Ag alloy," Journal of Electronic Materials 33(12), 1596-1607.

Ochoa, F., Williams, J. J. and Chawla, N. [2003] "Effects of cooling rate on the microstructure and tensile behavior of a Sn-3.5 wt.\%Ag solder," Journal of Electronic Materials 32(12), 1414-1420.

Oliver, W. C. and Pharr, G. M. [1992] "An improved technique for determining hardness and elastic modulus using load and displacement sensing indentation experiments," Journal of Materials Research 7(6), 1564-1583.

Pereira, P. D., Spinelli, J. E. and Garcia, A. [2013] "Combined effects of Ag content and cooling rate on microstructure and mechanical behavior of $\mathrm{Sn}-\mathrm{Ag}-\mathrm{Cu}$ solders," Materials 83 Design 45, 377-383.

-Ramakrishnan, N. and Arunachalam, V. S. [1993] "Effective elastic moduli of porous ceramic materials," Journal of the American Ceramic Society 76(11), 2745-2752.

-Sigelko, J., Choi, S., Subramanian, K. N., Lucas, J. P. and Bieler, T. R. [1999] "Effect of cooling rate on microstructure and mechanical properties of eutectic $\mathrm{Sn}-\mathrm{Ag}$ solder joints with and without intentionally incorporated $\mathrm{Cu} 6$ Sn 5 reinforcements," Journal of Electronic Materials 28(11), 1184-1188.

Swaddiwudhipong, S., Tho, K. K., Liu, Z. S. and Zeng, K. [2005] "Material characterization based on dual indenters," International Journal of Solids 8 Structures 42(1), 69-83.

Tho, K. K., Swaddiwudhipong, S., Liu, Z. S. and Zeng, K. [2005] "Simulation of instrumented indentation and material characterization," Materials Science and Engineering: A 390(1-2), 202-209.

-Xiao, G., Yuan, G., Jia, C., Yang, X., Li, Z. and Shu, X. [2014] "Strain rate sensitivity of $\mathrm{Sn}-3.0 \mathrm{Ag}-0.5 \mathrm{Cu}$ solder investigated by nanoindentation," Materials Science and Engineering: A 613(9), 336-339.

-Yang, L., Ge, J., Liu, H., Xu, L. and Bo, A. [2015] "Effect of cooling rate on the microstructure and mechanical properties of $\mathrm{Sn}-1.0 \mathrm{Ag}-0.5 \mathrm{Cu}-0.2 \mathrm{BaTiO} 3$ composite solder," Journal of Electronic Materials 44(11), 1-9. 
-Yang, W., Felton, L. E. and Messler, R. W. [1995] "The effect of soldering process variables on the microstructure and mechanical properties of eutectic $\mathrm{Sn}-\mathrm{Ag} / \mathrm{Cu}$ solder joints," Journal of Electronic Materials 24(10), 1465-1472.

-Zhu, L. N., Xu, B. S., Wang, H. D. and Wang, C. B. [2012] "Effect of residual stress on the nanoindentation response of (100) copper single crystal," Materials Chemistry 83 Physics 136(s 2-3), 561-565. 